\title{
SYNTHESIS OF DIMERATE ESTERS BY SOLVENT-FREE METHOD
}

\author{
NOOR ARMYLISA'S ABU HASSAN*; NORLIA AMAT MOHTAR ${ }^{\star *}$; SITI HAZIRAH MOHAMAD FAUZI*; \\ YEONG SHOOT KIAN*; HAZIMAH ABU HASSAN ${ }^{*}$ and ZAINAB IDRIS*
}

\begin{abstract}
Dimerate ester is normally used as lubricant base stock. Herein, we highlighted the preparation of several C36 dimerate esters derived from C36 dimer acid and medium chain length alcohols, i.e. 1-octanol, 1-hexanol and 2-ethylhexanol without the need for either solvent or catalyst but drying agent, $3 \AA$ molecular sieve $(3 \AA$

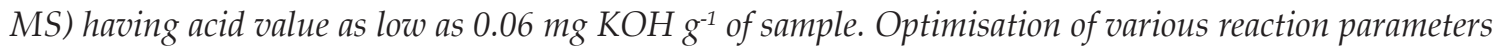
such as temperature, molar ratio, reaction time and water removal set-up was also carried out. The most affecting factors in synthesising low acid value $C_{36}$ dimerate ester are reaction temperature and efficiency of water removal. The esterification was carried out under optimum conditions by refluxing at $200^{\circ} \mathrm{C}$ for 24 hr using 1:4.5 molar ratio of $C_{36}$ dimer acid/alcohol in the presence of $15 \%$ w/w of $3 \AA \mathrm{MS}$.
\end{abstract}

Keywords: $\mathrm{C}_{36}$ dimer acid, $\mathrm{C}_{36}$ dimerate ester, lubricant base stock, esterification, self-catalysed esterification, acid value.

Date received: 2 September 2016; Sent for revision: 6 September 2016; Received in final form: 18 October 2016 ; Accepted: 22 November 2016.

\section{INTRODUCTION}

Dimer acids are commonly derived from unsaturated fatty acids mainly consist of oleic and linoleic acids such as tall oil and high oleic tallow (Elsasser and McCargar, 2001). Some dimer acids are produced from erucic acid, a monounsaturated omega-9 fatty acid of rapeseed oil (Morway et al., 1954). Palm oil or so-called golden crop, that contains oleic acid as one of the major fatty acid $(37.1 \%)$ as well as linoleic acid $(8.1 \%$ ) (Tan and Nehdi, 2012) can be used as a renewable feedstock for production of dimer acid. This dimer acid appeared as very viscous light yellow liquid and is widely used as raw material in the polymeric synthesis of fatty polyamides for

Malaysian Palm Oil Board, 6 Persiaran Institusi, Bandar Baru Bangi, 46000 Kajang, Selangor, Malaysia. E-mail: noor.armylisas@mpob.gov.my

* 5 Jalan HP 3/1, Hill Park, 43500 Semenyih, Selangor, Malaysia.

* 7 Jalan $3 / 22$, 43650 Bandar Baru Bangi, Selangor, Malaysia. application as resins (Mohammad et al., 2013) and hot melt adhesives (Ghasem, 2014). It is a useful polymer building block because they are able to impart the highly desirable properties of flexibility, elasticity and high impact strength to many polymer products. Besides polyamides, $\mathrm{C}_{36}$ dimerate esters which commonly used as chain oils, $2 \mathrm{~T}$ and $4 \mathrm{~T}$ oils (Randles, 2006) can be derived by esterification of $\mathrm{C}_{36}$ dimer acid and alcohol.

Dimerate esters generally have good thermal and oxidant stability which make them an excellent lubricant. Furthermore, the stability can be improved by hydrogenation of the double bonds. This diester is commonly used in two-stroke, predominantly in marine application as it provides low smoke properties and good biodegradability for spilled or combusted oil. The degree of biodegradability of esters are generally higher than corresponding hydrocarbons (Buenemann et al., 2003). Several patents have been filed on the use of dimer esters for many non-polymer industrial chemicals such as synthetic lubricants (Henry and Tierney, 1962; Matuszak and Craven, 1958; Tierney, 1960) and lubricant additives (Rutkowski and Szykowski, 1976). 
Esterification is a commonly used synthetic reaction which require presence of acid catalyst either homo- or heterogeneous catalyst to drive the reaction forward. Mandake et al. (2013) showed the acceleration of reaction rate in the presence of $10 \% \mathrm{w} / \mathrm{w}$ of Amberlyst $15^{\circledast}$ which afforded 54\% conversion in $3 \mathrm{hr}$ in contrast to only $14 \%$ conversion for non-catalytic esterification of acetic acid and methanol (1:3 molar ratio) within the same period of time. Conventionally, the esterification reaction is carried out in the presence of homogeneous inorganic catalyst such as sulphuric (Kale et al., 1991; Zeki et al., 2010), sulphonic and hydrochloric acid. To date, this trend has shifted towards the use of heterogeneous catalysts due to their several advantages over homogeneous catalysts. Numerous studies had been carried out for esterification reaction catalysed by various types of solid catalysts such as ion-exchange resin, i.e. Amberlyst $15^{\circledR}$ (Kirbaslar et al., 2001; Toor et al., 2011) and Tulsion ${ }^{\circledR}$ (Patil and Kulkarni, 2014). Several studies on acid-catalysed preparation of $\mathrm{C}_{36}$ dimerate with various short-chain alcohols (Burg and Kleiman, 1991; Kale et al., 1991) and their applications have been reported in several publications and patents (Henry and Tierney, 1962; Tierney, 1960) which showed the importance of the dimerates as versatile products such as lubricants, lubricant additives, surface-active agents and corrosion and rust inhibitors. Kale et al. (1991) had previously described preparation of $\mathrm{C}_{36}$ dimer ester in the presence of $1 \%(\mathrm{w} / \mathrm{w})$ of sulphuric acid $\left(\mathrm{H}_{2} \mathrm{SO}_{4}\right)$ in benzene as an azeotropic solvent. However, no studies of the spontaneous esterification of $\mathrm{C}_{36}$ dimer acid have been reported. In the world of organic synthesis, greener methods of chemical synthesis is an attractive field of research. The concept of green chemistry is the design of chemical products and / or processes that reduce or eliminate the use or generation of hazardous substances. In this study, we emphasised several principles of green chemistry (Anastas and Warner, 1998) in the synthesis of $\mathrm{C}_{36}$ dimerate ester using renewable feedstock under mild conditions without the need for either solvent or catalyst.

\section{MATERIALS AND METHODS}

\section{Materials}

Hydrogenated $\mathrm{C}_{36}$ dimer acid was purchased from supplier of Sigma Aldrich. 1-Butanol and 1-octanol were purchased from Fischer Scientific (United Kingdom) while 2-propanol was purchased from Friendemann Schmidt and $3 \AA$ MS (powder form) was obtained from Sigma Aldrich. All of the reagents were used as supplied, without any purification and stored according to the manufacturer's recommendations

\section{Methods}

Acid value determination. The acid value is defined as number of milligrams of potassium hydroxide $(\mathrm{KOH})$ required to neutralise the fatty acids in $1 \mathrm{~g}$ of sample and was determined using MPOB Test Method c2.7. This method is applicable to all fatty acids and polymerised fatty acids (MPOB, 2005a).

The acid value is expressed as

Acid value $=\left(\frac{56.1 \times \mathrm{V} x \mathrm{M}}{m}\right) \mathrm{mg} \mathrm{KOH} \mathrm{g}^{-1}$

where,

$V$ is the volume in millilitres $(\mathrm{ml})$ of standard volumetric $\mathrm{KOH}$ used;

$M$ is the exact concentration in mole per litre of the standard volumetric $\mathrm{KOH}$ solution used; and

$m$ is the mass in grams of the test portion.

For accuracy in the determination of acid value, the sample size used is varied, as recommended in MPOB Test Method p2.5 (Table 1).

Decrease in acid value is a good indicator of reaction progress for the reaction with $\mathrm{C}_{36}$ dimer acids as the limiting reactant (Mohammad et al., 2013).

Infra-red (IR) spectroscopy. Infrared spectra were recorded as neat samples using a Perkin-Elmer Spectrum 100 FT-IR Spectrometer. All IR data were manipulated using Spectrum v6.3.5 software.

Nuclear magnetic resonance (NMR) spectroscopy. The ${ }^{1} \mathrm{H}$ - and ${ }^{13} \mathrm{C}-\mathrm{NMR}$ spectra were recorded in Fourier transform mode on a $400 \mathrm{MHz}$ Bruker Avance III using the specified deuterated solvent. All spectra were processed using MestR-C Nova software. The chemical shift for both ${ }^{1} \mathrm{H}$ - and ${ }^{13} \mathrm{C}-\mathrm{NMR}$ spectra were recorded in ppm and were referenced to the residual solvent peak or TMS peak. Multiplicities in the NMR are described as: $s=$ singlet,$d=$ doublet,$t=$ triplet,$t d=$ triplet of

TABLE 1. RECOMMENDED SAMPLE SIZE

\begin{tabular}{lcc}
\hline Acidity (FFA) & $\begin{array}{c}\text { Weight of sample } \\
(\mathbf{1 0} \%), \mathbf{g}\end{array}$ & $\begin{array}{c}\text { Weighing } \\
\text { accuracy } \mathbf{(} \mathbf{\mathbf { g }})\end{array}$ \\
\hline 0 to 1 & 20.0 & 0.05 \\
1 to 4 & 10.0 & 0.02 \\
4 to 15 & 2.5 & 0.01 \\
15 to 75 & 0.5 & 0.001 \\
75 and over & 0.1 & 0.0002
\end{tabular}

Note: FFA - free fatty acid.

Source: MPOB (2005b). 
doublets, $q=$ quartet, sept. = septet, $m=$ multiplet, $\mathrm{br}=$ broad, coupling constants, $J$ values are reported in Hertz $(\mathrm{Hz})$.

\section{General Procedure for Non-catalytic Esterification of $\mathrm{C}_{36}$ Dimer Acid}

Alcohol of 4.5 equiv was added into a single neck $500 \mathrm{ml}$ round bottom flask containing hydrogenated $\mathrm{C}_{36}$ dimer acid $(114.0 \mathrm{~g}, 0.2 \mathrm{~mol})$ and $3 \AA \mathrm{MS}(15 \%$ $\mathrm{w} / \mathrm{w}, 17.2 \mathrm{~g})$. This flask was then attached to a DeanStark apparatus and the mixture was subjected to heating at $200^{\circ} \mathrm{C}$ for $24 \mathrm{hr}$ after which the reaction was ceased. The reaction was then cooled down to ambient temperature. The $3 \AA$ MS was filtered off and purification of the crude compound was carried out via vacuum distillation for the removal of excess of alcohol and remaining water molecule.

Hydrogenated $C_{36}$ dioctyl dimerate. Prepared according to the general procedure for non-catalytic esterification of $\mathrm{C}_{3}$ dimer acid 1-octanol $(142.2 \mathrm{ml}$, $0.9 \mathrm{~mol}$ ). The product (Figure 1) was isolated as yellowish oil $(143.0 \mathrm{~g}, 76 \%)$ and $\mathrm{v}_{\max }$ (neat) $/ \mathrm{cm}^{-1}$ 2925, 2856, 1797, 1470, 1977, 1250, 1170 and 1118; ${ }^{1} \mathrm{H}$ NMR (500 MHz, $\left.\mathrm{CDCl}_{3}\right) \delta 4.04(\mathrm{t}, J=7.0 \mathrm{~Hz}, 4 \mathrm{H})$, $2.27(\mathrm{t}, J=7.2 \mathrm{~Hz}, 4 \mathrm{H}), 1.60$ (br. $\mathrm{s}, 10 \mathrm{H}), 1.44-1.03$ $(\mathrm{m}, 68 \mathrm{H}), 0.87(\mathrm{t}, J=6.5 \mathrm{~Hz}, 14 \mathrm{H})$.

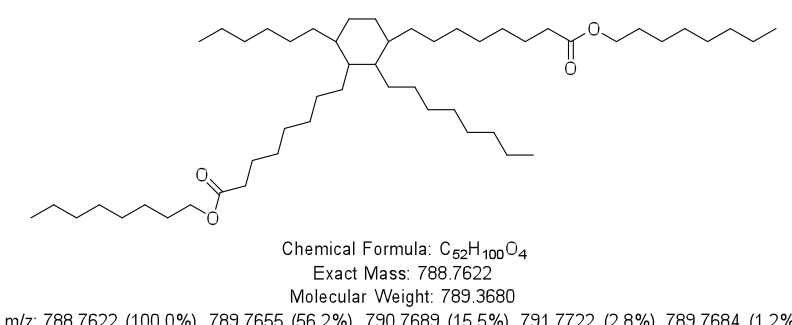

m/z: 788.7622 (100.0\%), 789.7655 (56.2\%), 790.7689 (15.5\%), 791.7722 (2.8\%), 789.7684 (1.2\%) Elemental Analysis: C, $79.12 ; \mathrm{H}, 12.77 ; 0,8.11$

Figure 1. Structure of hydrogenated $C_{36}$ dioctyl dimerate.

Hydrogenated $C_{36}$ di-(2-ethylhexyl) dimerate. Prepared according to the general procedure from 2-ethylhexanol ( $0.9 \mathrm{~mol}, 141 \mathrm{ml})$. The product (Figure 2) was isolated as yellowish oil $(151.9 \mathrm{~g}, 96 \%)$ and $\mathrm{v}_{\max }$ (neat) $/ \mathrm{cm}^{-1} 2925,2856,1797,1470,1977,1250$, 1170 and 1118; ${ }^{1} \mathrm{H}$ NMR (500 MHz, $\left.\mathrm{CDCl}_{3}\right) \delta 3.99-$

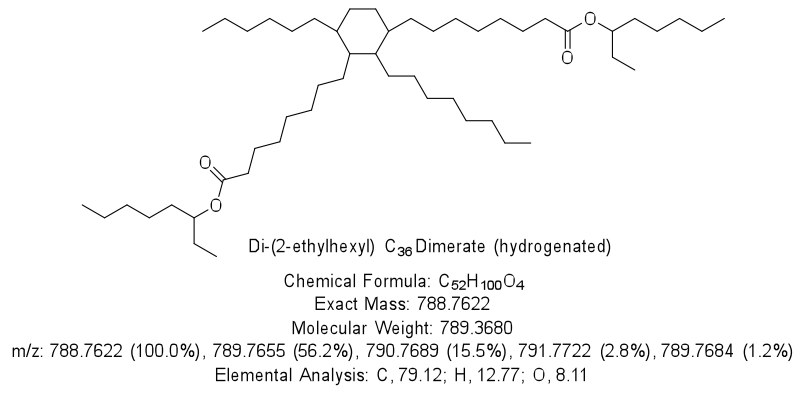

Figure 2. Structure of hydrogenated $C_{36}$ di-(2-ethylhexyl) dimerate. $3.94(\mathrm{~m}, 4 \mathrm{H}), 2.28(\mathrm{t}, J=7.6 \mathrm{~Hz}, 4 \mathrm{H}), 1.60-1.52(\mathrm{~m}$, $10 \mathrm{H}), 1.44-1.03(\mathrm{~m}, 68 \mathrm{H}), 0.89-0.81(\mathrm{~m}, 14 \mathrm{H})$.

Hydrogenated $C_{36}$ dihexyl dimerate. Prepared according to the general procedure from 1-hexanol (0.9 mol, $141 \mathrm{ml})$. The product (Figure 3$)$ was isolated as yellowish oil $(124.7 \mathrm{~g}, 85 \%)$ and $\mathrm{v}_{\max }$ (neat) $/ \mathrm{cm}^{-1}$ 2925, 2856, 1797, 1470, 1977, 1250, 1170 and 1118; ${ }^{1} \mathrm{H}$ $\operatorname{NMR}\left(500 \mathrm{MHz}, \mathrm{CDCl}_{3}\right) \delta 4.05(\mathrm{t}, J=6.6 \mathrm{~Hz}, 4 \mathrm{H})$, $2.28(\mathrm{t}, J=7.6 \mathrm{~Hz}, 4 \mathrm{H}), 1.60$ (br. $\mathrm{s}, 10 \mathrm{H}), 1.44-1.03$ $(\mathrm{m}, 60 \mathrm{H}), 0.87(\mathrm{~m}, 14 \mathrm{H})$.

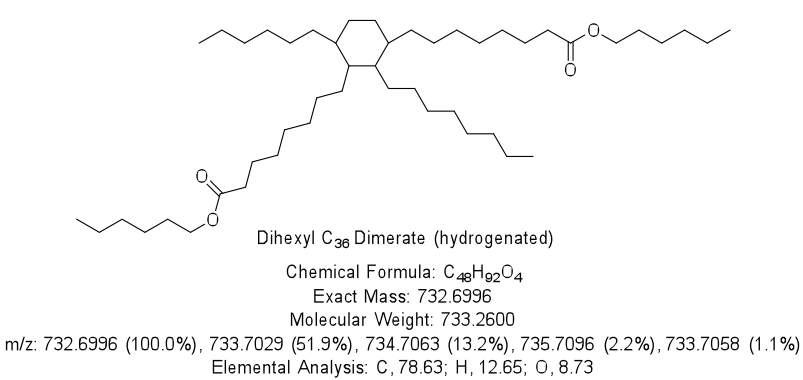

Figure 3. Structure of hydrogenated $C_{36}$ dihexyl dimerate.

\section{RESULTS AND DISCUSSION}

We aimed to prepare $\mathrm{C}_{36}$ dimerate having acid value less than $1.0 \mathrm{mg} \mathrm{KOH} \mathrm{g}^{-1}$ of sample. Initially, we investigated the synthesis of $\mathrm{C}_{36}$ dimerate ester via esterification of $\mathrm{C}_{36}$ dimer acid with 1-octanol. The reaction was carried out by heating the reaction mixture up to $200^{\circ} \mathrm{C}$ in 1:4.5 mole ratio $\left(C_{36}\right.$ dimer acid/1-octanol), equipped with Dean-Stark apparatus producing the corresponding dioctyl dimerate. This preliminary study showed the capability of the $C_{36}$ dimer acid to self-catalyse the esterification reaction.

The reaction parameters including temperature, molar ratio and reaction time in the absence of acid catalyst and organic solvent were optimised. Above all, the design of the experimental set-up was also investigated in order to efficiently remove water that would drive the esterification reaction to completion.

\section{Study of Reaction Conditions and Parameters}

Reaction temperature. Effect of reaction temperature in the esterification of $\mathrm{C}_{36}$ dimer acid was studied by monitoring the acid value reduction; and four different reaction temperatures were investigated i.e. $130^{\circ} \mathrm{C}, 150^{\circ} \mathrm{C}, 170^{\circ} \mathrm{C}$ and $200^{\circ} \mathrm{C}$. As can be seen in Figure 4, the reaction carried out at $200^{\circ} \mathrm{C}$ gave the fastest rate and the lowest acid value throughout the reaction. In the first hour, reactions at all temperature gave nearly similar reaction rate but at $200^{\circ} \mathrm{C}$, the acid number decreased to $54 \mathrm{mg} \mathrm{KOH} \mathrm{g}^{-1}$ of sample, more than $75 \%$ reduction from initial acid value of $200 \mathrm{mg} \mathrm{KOH} \mathrm{g}^{-1}$ of sample. After $7 \mathrm{hr}$ of reaction, the 


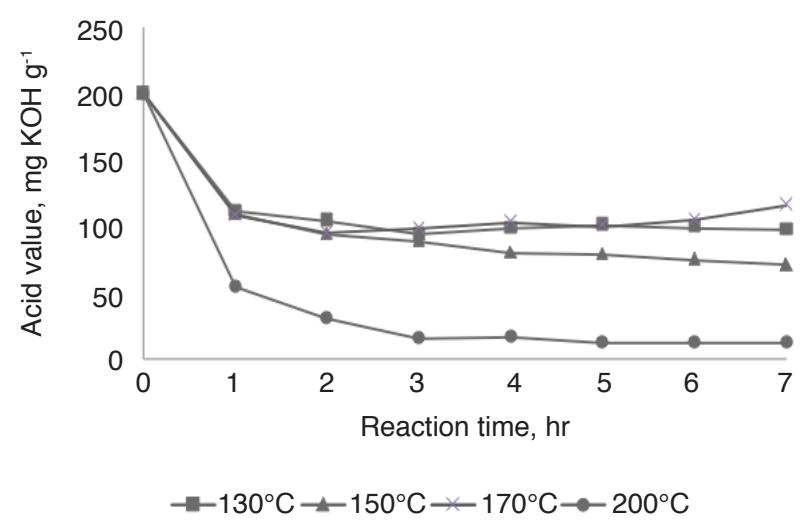

Figure 4. Effect of reaction temperature on acid value at 1:2 ratio of $C_{36}$ dimer acid/1-octanol.

acid value went down to $12 \mathrm{mg} \mathrm{KOH} \mathrm{g}^{-1}$ of sample while reaction at temperature $130^{\circ} \mathrm{C}, 150^{\circ} \mathrm{C}$, and $170^{\circ} \mathrm{C}$ gave end products with acid value of 116,97 , and $71 \mathrm{mg} \mathrm{KOH} \mathrm{g}^{-1}$ of sample, respectively.

The maximum temperature for this reaction was set no more than $200^{\circ} \mathrm{C}$ due to the boiling point of 1 -octanol i.e. $195^{\circ} \mathrm{C}$ as it was reported that higher amount of heat would be released at higher reaction temperature which may lead to runaway reaction (Syed et al., 2010). Several studies on esterification of acetic acid with different alcohols showed that the reaction can be accelerated forward with the increment of temperature (Kirbaslar et al., 2001; Mandake et al., 2013; Toor et al., 2011; Zeki et al., 2010), which is an indication of absence of mass transfer effect and this is in accordance with our results.

Molar ratio and reaction time. Stoichiometrically, two moles of 1-octanol is required to react on both ends of the $C_{36}$ dimer acid. Thus, initial reaction was conducted using 1:2 mole ratio of $C_{36}$ dimer acid / 1 octanol. However, the acid value obtained from the reaction was $17.32 \mathrm{mg} \mathrm{KOH} \mathrm{g}^{-1}$ of sample after $8 \mathrm{hr}$, while the desired acid value of the ester product should be less than $1.0 \mathrm{mg} \mathrm{KOH} \mathrm{g}^{-1}$ of sample. The reactions were then carried out by increasing the number of mole of 1-octanol used in the reaction $\left(\mathrm{C}_{36}\right.$ dimer acid/1-octanol); 1:2.2, 1:2.6, 1:3.3 and 1:4.5. After $8 \mathrm{hr}$ of reaction, the acid values obtained were $11.06,11.40,10.68$, and $6.93 \mathrm{mg} \mathrm{KOH} \mathrm{g}^{-1}$ of sample, respectively as illustrated in Figure 5.

The acid value obtained was the lowest in the reaction using 1:4.5 mole ratio of $C_{36}$ dimer acid/1octanol, i.e. $6.39 \mathrm{mg} \mathrm{KOH} \mathrm{g}^{-1}$ of sample. Hence, we decided to use this ratio as the optimum mole ratio for our subsequent reactions.

Increasing the mole ratio of 1-octanol with respect to $\mathrm{C}_{36}$ dimer acid is unfavourable as this may reduce the reaction rate gradually as reported by Kale et al. (1991) as the mole ratio of $C_{36}$ dimer acid to 2-propanol changed from 1:5 to 1:10 and further increment of alcohol used may cause excess

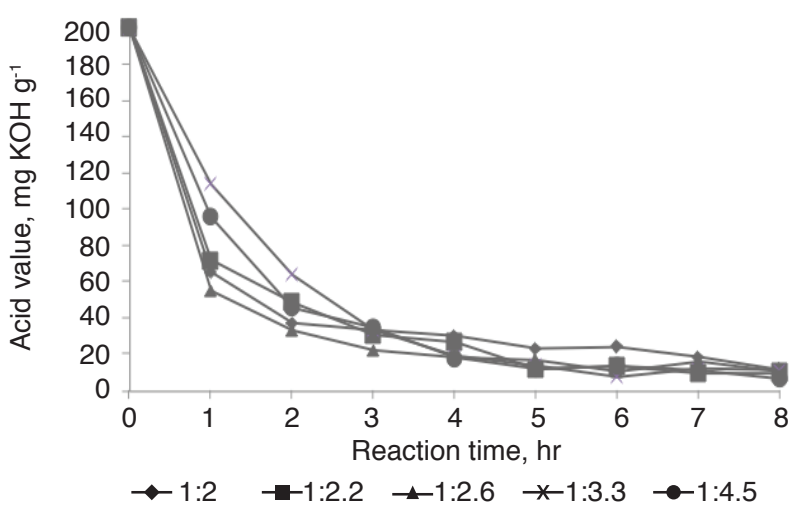

Figure 5. Acid value profile at different mole ratio of $C_{36}$ dimer acid/1-octanol at $200^{\circ} \mathrm{C}$.

dilution of the reaction mixture. All the reactions (having different molar ratios of $\mathrm{C}_{36}$ dimer acid to octanol) were then prolonged to $40 \mathrm{hr}$ and the acid values were tabulated (Table 2). As expected, for all entries, the acid value decreased as the reaction time was extended.

TABLE 2. EFFECT OF DIFFERENT MOLE RATIO OF $\mathrm{C}_{36}$ DIMER ACID/1-OCTANOL ON THE ACID VALUE

\begin{tabular}{|c|c|c|c|}
\hline \multirow[t]{2}{*}{ Entry } & \multirow[t]{2}{*}{$\begin{array}{c}\text { Molar ratio of } \mathrm{C}_{36} \\
\text { dimer acid/1-octanol }\end{array}$} & \multicolumn{2}{|c|}{$\begin{array}{c}\text { Acid value } \\
\left(\mathrm{mg} \mathrm{KOH} \mathrm{g}^{-1}\right)\end{array}$} \\
\hline & & $8 \mathrm{hr}$ & $40 \mathrm{hr}$ \\
\hline 1 & $1: 2.0$ & 17.32 & 8.40 \\
\hline 2 & $1: 2.2$ & 11.06 & 6.83 \\
\hline 3 & $1: 2.6$ & 11.40 & 6.53 \\
\hline 4 & 1:3.3 & 10.68 & 6.96 \\
\hline 5 & $1: 4.5$ & 6.93 & 5.95 \\
\hline
\end{tabular}

Effect of water in the reaction. In the esterification reaction, the presence of water due to its occurrence in the raw material and as a side product of esterification can reverse the reaction. Therefore, the removal of water is very crucial for this reaction to bring the reaction forward and thus, obtain high yield of product.

Effect of water on moisture sensitive reaction has been reported in several studies (Elsasser and McCargar, 2001; Ma et al., 1998; Park et al., 2010; Tran et al., 2013). Park et al. (2010) reported that in the esterification of oleic acid of soyabean, initial water content as low as $1 \%$ of oil is sufficient to accelerate the inverse reaction. In addition, catalyst activity (for example Amberlyst $15^{\circledR}$ ) gradually decreased due to catalyst poisoning and poor accessibility of reactants to acid sites in the presence of water. In transesterification of beef tallow and methanol $(\mathrm{MeOH})$ catalysed by sodium hydroxide $(\mathrm{NaOH})$, water content above $0.06 \%$ will significantly reduce the fatty acid methyl esters (FAME) produced (Ma et al., 1998). 
In the attempt to efficiently remove water during the reaction including the use of Dean-Stark apparatus, $3 \AA$ MS addition into the reaction mixture - under the optimum reaction conditions shall be discussed.

\section{a) Dean-Stark apparatus}

In this study, the use of Dean-Stark has been proven to significantly improve the efficiency of the reaction as monitored by the reduction of acid value. This is accompanied by several other factors such as experimental set-up design, suitable flask size for amount of starting materials (reactants), and proper heat distribution to ensure efficient water removal.

In the initial design of the experimental set-up, the Dean-Stark apparatus was attached to Claisen adapter and three-neck round bottom flask in which the other two necks were used to fit in the thermometer adapter and nitrogen $\left(\mathrm{N}_{2}\right)$ gas inlet. The reaction was carried out under optimum conditions: temperature of $200^{\circ} \mathrm{C}, 1: 4.5$ molar ratio $\left(\mathrm{C}_{36}\right.$ dimer acid / 1-octanol $)$ in $24 \mathrm{hr}$. This reaction setup, however, did not give the best results probably due to inefficient water removal.

On the basis of reducing the numbers of adapters / connectors used, the Dean-Stark apparatus was then directly attached to the flask. The singleneck flask also helped to avoid water accumulation at the side ports. With the same reaction conditions, the acid value was further reduced using this set-up.

Table 3 showed the acid values obtained under optimum conditions but at various reaction times for the two Dean-Stark set-ups. The second set-up managed to reduce the acid value to $2.37 \mathrm{mg} \mathrm{KOH}$ $\mathrm{g}^{-1}$ on $24 \mathrm{hr}$ compared to $5.95 \mathrm{mg} \mathrm{KOH} \mathrm{g}^{-1}$ for the initial set-up even after $40 \mathrm{hr}$ reaction.

TABLE 3. ACID VALUE OF DIFFERENT REACTION SET-UP

\begin{tabular}{llcc}
\hline \multirow{2}{*}{ Reaction set-up } & \multicolumn{3}{c}{ Acid value (mg KOH g $\mathbf{~ g}^{-1}$ of sample) } \\
\cline { 2 - 4 } & $\mathbf{8} \mathbf{~ h r}$ & $\mathbf{2 4} \mathbf{~ h r}$ & $\mathbf{4 0 ~ h r}$ \\
\hline Initial & 6.93 & - & 5.95 \\
Final & 6.39 & 2.37 & - \\
\hline
\end{tabular}

\section{b) Addition of $3 \AA \mathrm{MS}$}

Molecular sieves are considered as a generalpurpose drying agent in both polar and nonpolar media. Molecular sieves have been shown to remove water, alcohols (including methanol and ethanol), and hydrochloric acid from such systems as ketimine and enamine syntheses, ester condensations, and the conversion of unsaturated aldehydes to polyenals (Aldrich, 2015).

The purpose of adding $3 \AA$ MS into the reaction was to absorb the remaining water molecule in the reaction mixture. Under the optimal conditions, using $100 \mathrm{ml}$ round bottom flask the amount of $3 \AA$ MS loaded into the reaction mixture up to $4.4 \% \mathrm{w} / \mathrm{w}$ affording dioctyl dimerate with acid value of 0.75 mg KOH g-1 of sample (Table 4). However, when the reaction was up-scaled using $500 \mathrm{ml}$ flask, $15 \% \mathrm{w} / \mathrm{w}$ $3 \AA$ MS was required to obtain acid value below 1.0 $\mathrm{mg} \mathrm{KOH} \mathrm{g-1}$.

TABLE 4. EFFECT OF $3 \AA ̊$ MOLCULAR SIEVES ADDITION. REAGENTS AND CONDITIONS: $200^{\circ} \mathrm{C}, 24 \mathrm{hr}$, DEAN-STARK APPARATUS, $\mathrm{C}_{36}$ DIMER ACID/1-OCTANOL (1:4.5)

\begin{tabular}{lcccc}
\hline Entry & $\begin{array}{c}\text { No. of mole of } \\
\mathrm{C}_{36} \text { dimer acid }\end{array}$ & $\begin{array}{c}\text { Size of flask } \\
(\mathbf{m l})\end{array}$ & $\begin{array}{c}\text { Molecular } \\
\text { sieves } \\
(\%, \mathbf{w} / \mathbf{w})\end{array}$ & $\begin{array}{c}\text { Acid value } \\
(\mathbf{m g} \mathbf{~ K O H} \\
\left.\mathbf{g}^{-1}\right)\end{array}$ \\
\hline 1 & 0.04 & 100 & - & 2.37 \\
2 & 0.04 & 100 & 2.2 & 1.49 \\
3 & 0.04 & 100 & 4.4 & 0.75 \\
4 & 0.20 & 500 & 4.4 & 1.36 \\
5 & 0.20 & 500 & 10.0 & 1.04 \\
6 & 0.20 & 500 & 15.0 & 0.54 \\
\hline
\end{tabular}

\section{Self-catalysed Esterification of $\mathrm{C}_{36}$ Dimer Acid with Different Chain of Alcohols}

The standard acid-catalysed reaction involves reversible protonation at the carbonyl oxygen followed by the rate-limiting attack of the alcohol upon the protonated carboxylic acid intermediate (Figure 6) (Maskill, 1990).

Profiling the reaction between $\mathrm{C}_{36}$ dimer acid and 1-octanol has demonstrated esterification of $C_{36}$ dimer acid to generate the corresponding mono- and diester product seemingly took place relatively fast. At $4 \mathrm{hr}$ mark, the $\mathrm{C}_{36}$ dimer acid was fully consumed producing both mono- and diester in a nearly equal amount. In the presence of excess of 1-octanol, the monoesters further react to yield the corresponding diester (Figure 7).

This finding is really unanticipated as the reaction conditions in which we carried out the esterification reaction was really mild and without the presence of any organic solvent or catalyst. High reaction temperature is probably the main factor contributing to $100 \%$ conversion of $\mathrm{C}_{36}$ dimer acid within $4 \mathrm{hr}$ of reaction. At $200^{\circ} \mathrm{C}$, water molecules present in the reaction mixture can be removed by evaporation into the Dean-Stark apparatus.

Previously, several non-catalytic esterification of methanol with monocarboxylic acid such as acetic acid (Mandake et al., 2013; Pöpken et al., 2000) and lactic acid (Sanz et al., 2002) had been reported, in which the esterification was found to be catalysed by $\mathrm{H}^{+}$generated by the carboxylic acid itself.

According to Ashworth et al. (2012), theoretically, self-catalysed esterification will depend upon both on the esterification rate constant and the acid 


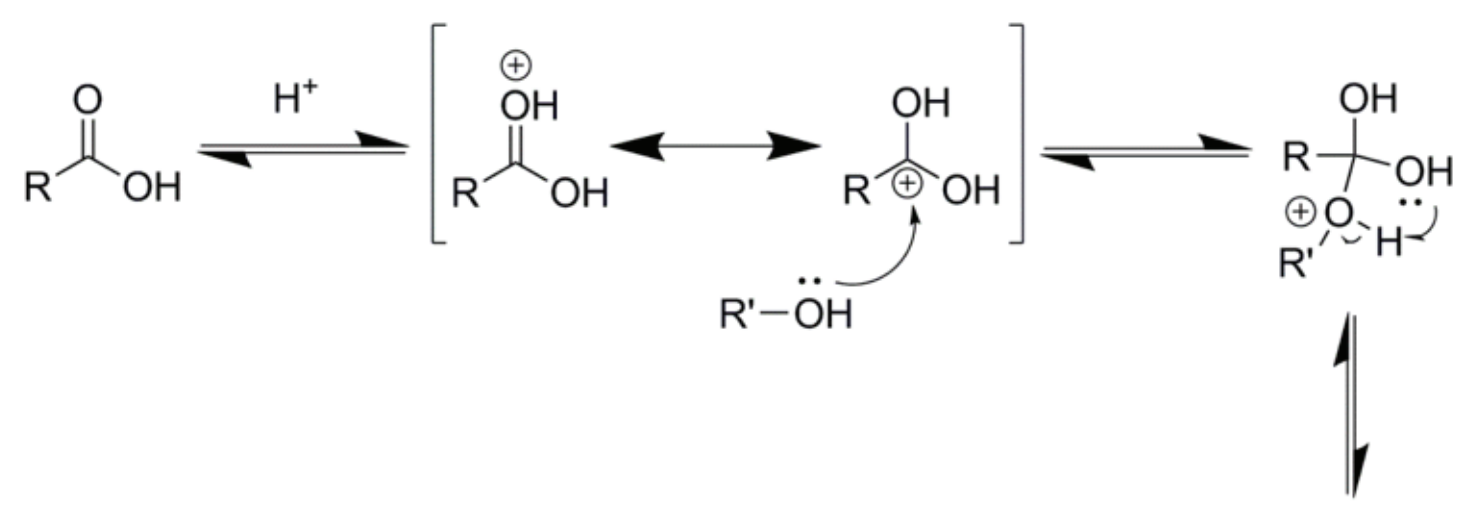

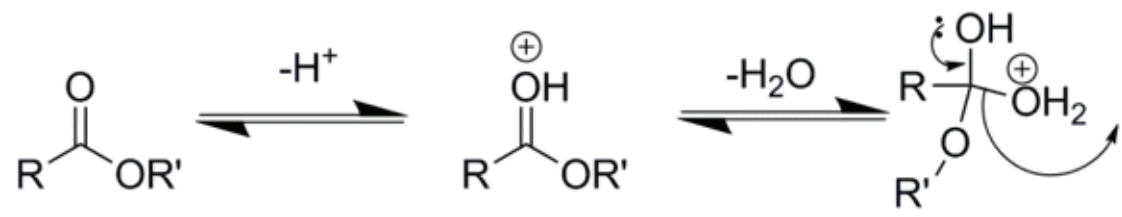

Figure 6. Mechanism of acid-catalysed esterification of carboxylic acids.

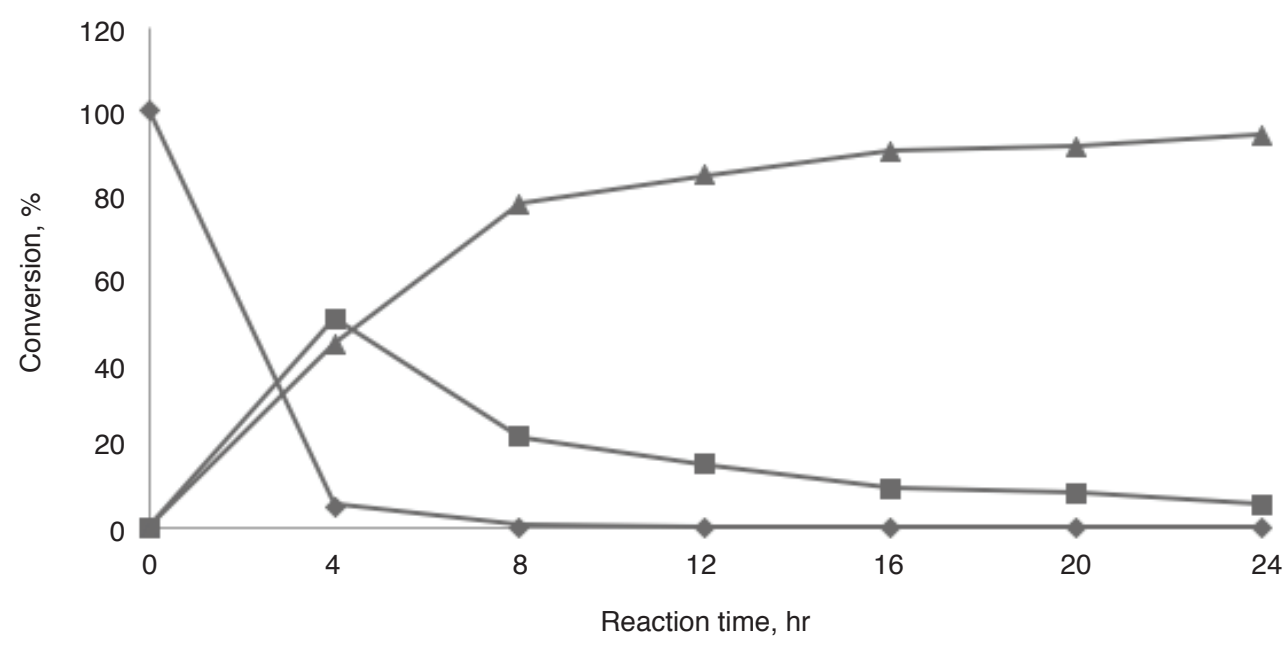

Figure 7. Time course vs. formation. Reagents and conditions: $200^{\circ} \mathrm{C}, \mathrm{C}_{36}$ dimer acid/1-octanol-1:4.5, $24 \mathrm{hr}$.

dissociation constant, $K_{a}$. In relative to the acidity of the maleic acid in methanol, carboxylic acid with similar or higher acidity will be more likely to selfcatalyse following one-and-half-order rate law.

Esterification of $\mathrm{C}_{36}$ dimer acid in 1-octanol is occurring due to dissociation of the dicarboxylic acid producing $\mathrm{H}^{+}$to self-catalyse the reaction. This is assisted by efficient removal of water molecule to drive the reaction to completion.

Self-catalysed (or sometimes known as autocatalysed) esterification is also common in the synthesis of polyester. Polyesters are polymers synthesised from dicarboxylic acid and diol. One of the most common examples of polyester is polyethylene terephthalate (PET), derived from terephthalic acid and ethylene glycol. In the formation of polyester, the diacid monomer acts as its own catalyst for the esterification reaction. A comprehensive discussion on the kinetic studies of the self-catalysed polyester formation had been published in several books (Chanda, 2006; Duda and Penczek, 2005; Mandal, 2013).

As we accomplished the optimisation of reaction conditions for esterification of $\mathrm{C}_{36}$ dimer acid and 1-octanol followed by purification, we then applied these conditions and methods on esterification of several other alcohols, i.e. 1-hexanol, 2-ethyl-1-hexanol and 1-butanol. Very high acid value for dibutyl dimerate was obtained due to the incomplete conversion of $\mathrm{C}_{36}$ dimer acid (Table 5) which further confirmed by IR spectrum analysis.

\section{Product Purification via Vacuum Distillation}

It was determined that the crude product contained 1-octanol, which is used in excess in the reaction by the presence of broad $-\mathrm{OH}$ peak according to IR spectrum. Due to high boiling point 
TABLE 5. ACID VALUE OF $\mathrm{C}_{36}$ DIMERATE ESTERS

\begin{tabular}{lc}
\hline Alcohols & Acid value, $\mathbf{~ m g ~ K O H ~ g}^{-1}$ \\
\hline 1-Octanol & 0.54 \\
1-Hexanol & 0.06 \\
2-Ethyl-1-hexanol & 1.65 \\
1-Butanol & 30.10 \\
\hline
\end{tabular}

of 1-octanol, i.e. $195^{\circ} \mathrm{C}$, the removal of the starting material using simple distillation is not preferable. Hence, the purification of the crude product was carried out via distillation under reduced pressure. A vacuum distillation is used to distill the compound or the solvent off when the boiling point is too high (more than $150^{\circ} \mathrm{C}$ ) without significant decomposition.

The mixture was first heated up to desired temperature, i.e. $120^{\circ} \mathrm{C}$ and the vacuum pump was then started and the pressure was controlled manually and reduced down as low as $6.7 \times 10^{-2}$ mbar. The reduction of pressure should be carried out cautiously in order to avoid the product drawn into the receiving flask.

Referring to IR spectra analysis, complete removal of 1-octanol was confirmed by the absence of broad peak of $-\mathrm{OH}$ between $3200-3600 \mathrm{~cm}^{-1}$ and $\mathrm{C}-\mathrm{O}$ peak at $1058 \mathrm{~cm}^{-1}$ and strong peak of $\mathrm{C}=\mathrm{O}$ stretching of carboxylic acid at $1707 \mathrm{~cm}^{-1}$ (refer to Figure 8, red line). The formation of $\mathrm{C}_{36}$ dimerate ester is further confirmed using NMR analysis.

It was also determined that the compound contained carbonyl groups of ester from the peak at $1737 \mathrm{~cm}^{-1}$. The carbonyl stretching of the ester carbonyl group in the $\mathrm{C}_{36}$ dimerate ester is observed at slightly higher frequency than carbonyl of carboxylic acid. The complimentary peaks of $\mathrm{C}-\mathrm{O}$ stretches of the esters appeared at 1244, 1169, and $1118 \mathrm{~cm}^{-1}$.

The formation of the dioctyl dimerate can be further confirmed using NMR spectroscopic analysis (Figure 9). The appearance of triplet peak at $4.04 \mathrm{ppm}$ with coupling constant of $7.0 \mathrm{~Hz}$ shows the presence of ester.

The IR spectra of three other dimerate esters synthesised, i.e. dihexyl dimerate, di-(2-ethylhexyl) dimerate, and dibutyl dimerate have similar absorption showing presence of carbonyl group of ester at $1737 \mathrm{~cm}^{-1}$ (Figure 10). However, in the product of dibutyl dimerate, the presence of $\mathrm{C}_{36}$ dimer acid is shown with the absorption at 1710 $\mathrm{cm}^{-1}$. This result is an indicator of incomplete conversion of $\mathrm{C}_{36}$ dimer acid into dibutyl dimerate.

Under the optimised reaction conditions, high reaction temperature, i.e. $200^{\circ} \mathrm{C}$ is probably not suitable for esterification of $\mathrm{C}_{36}$ dimer acid and 1-butanol as 1-butanol has much lower boiling point, at $117.7^{\circ} \mathrm{C}$. Hence, 1-butanol evaporates easily under this reaction conditions. In other word, the optimised reaction conditions we emphasised for esterification of $\mathrm{C}_{36}$ dimer acid and 1-octanol is not appropriate for alcohol with low boiling point.

\section{CONCLUSION}

The $\mathrm{C}_{36}$ dimerate ester with acid value below $1.0 \mathrm{mg} \mathrm{KOH} \mathrm{g}^{-1}$ of sample has been successfully synthesised under optimum conditions of at $200^{\circ} \mathrm{C}$ for $24 \mathrm{hr}$ using 1:4.5 molar ratio of $\mathrm{C}_{36}$ dimer acid/

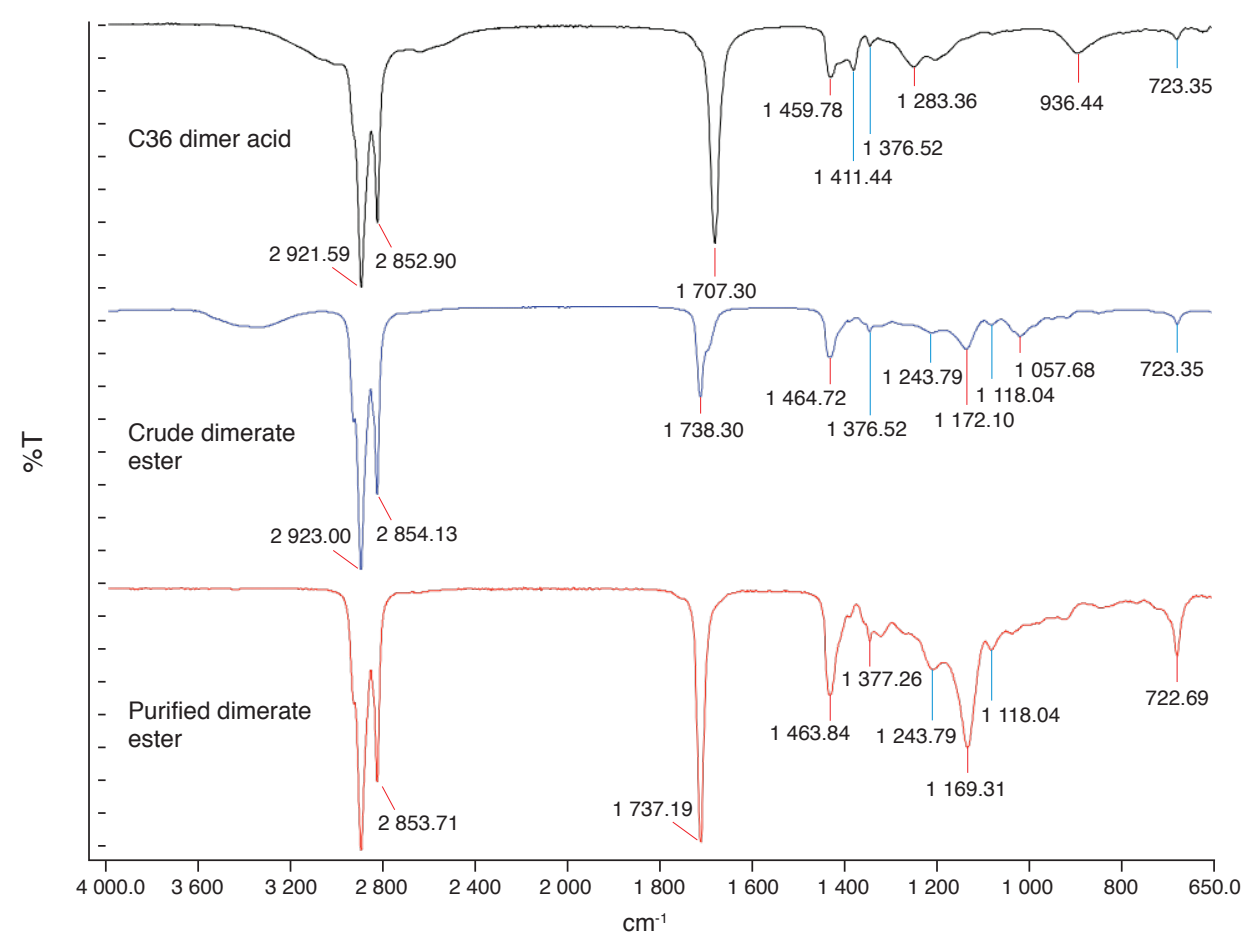

Figure 8. Infra-red spectra comparison of starting material, crude and purified dioctyl dimerate. 

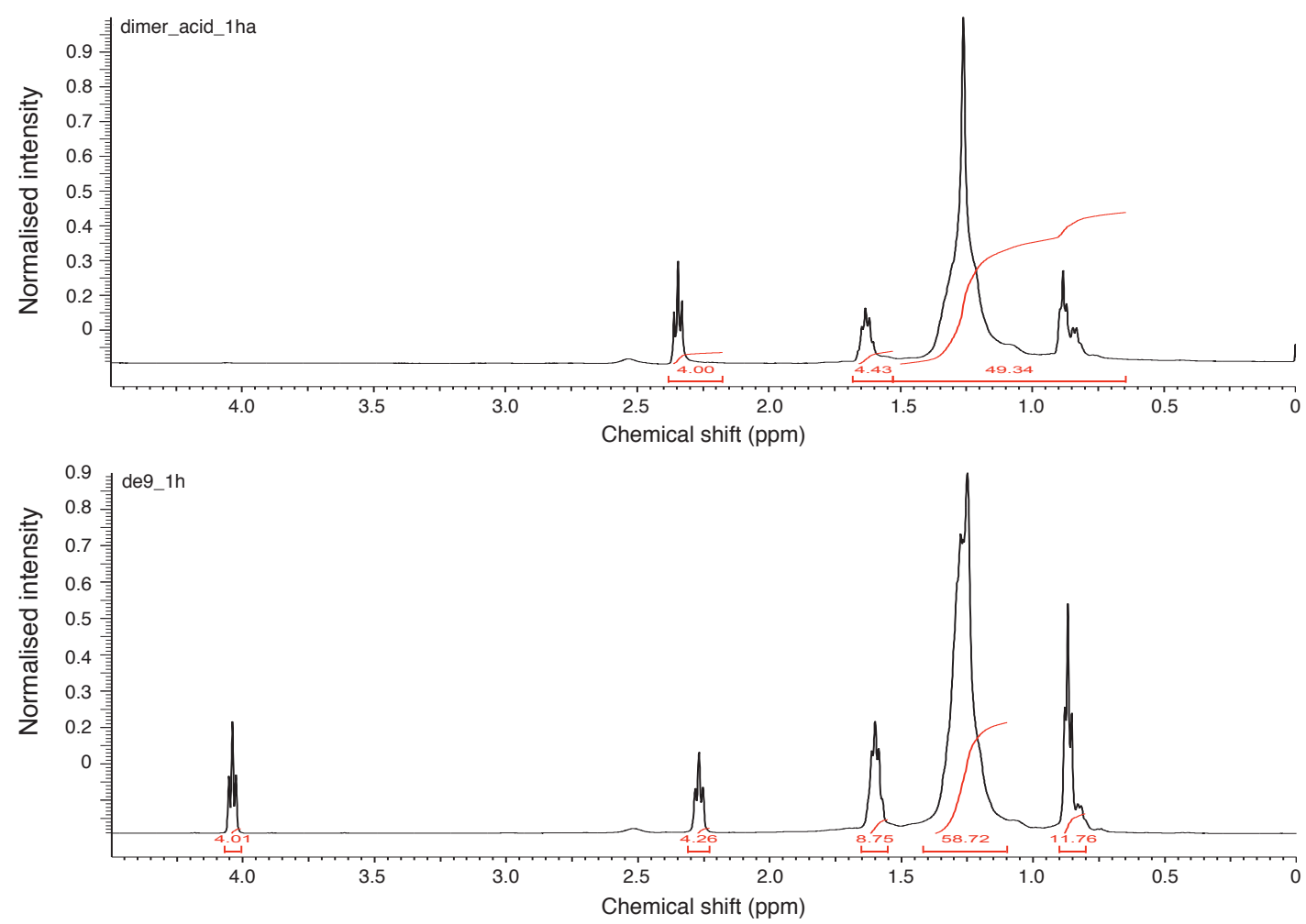

Figure 9. Nuclear magnetic resonance (NMR) spectra of hydrogenated $C_{36}$ dimer acid (a) and the corresponding product, dioctyl dimerate (b).

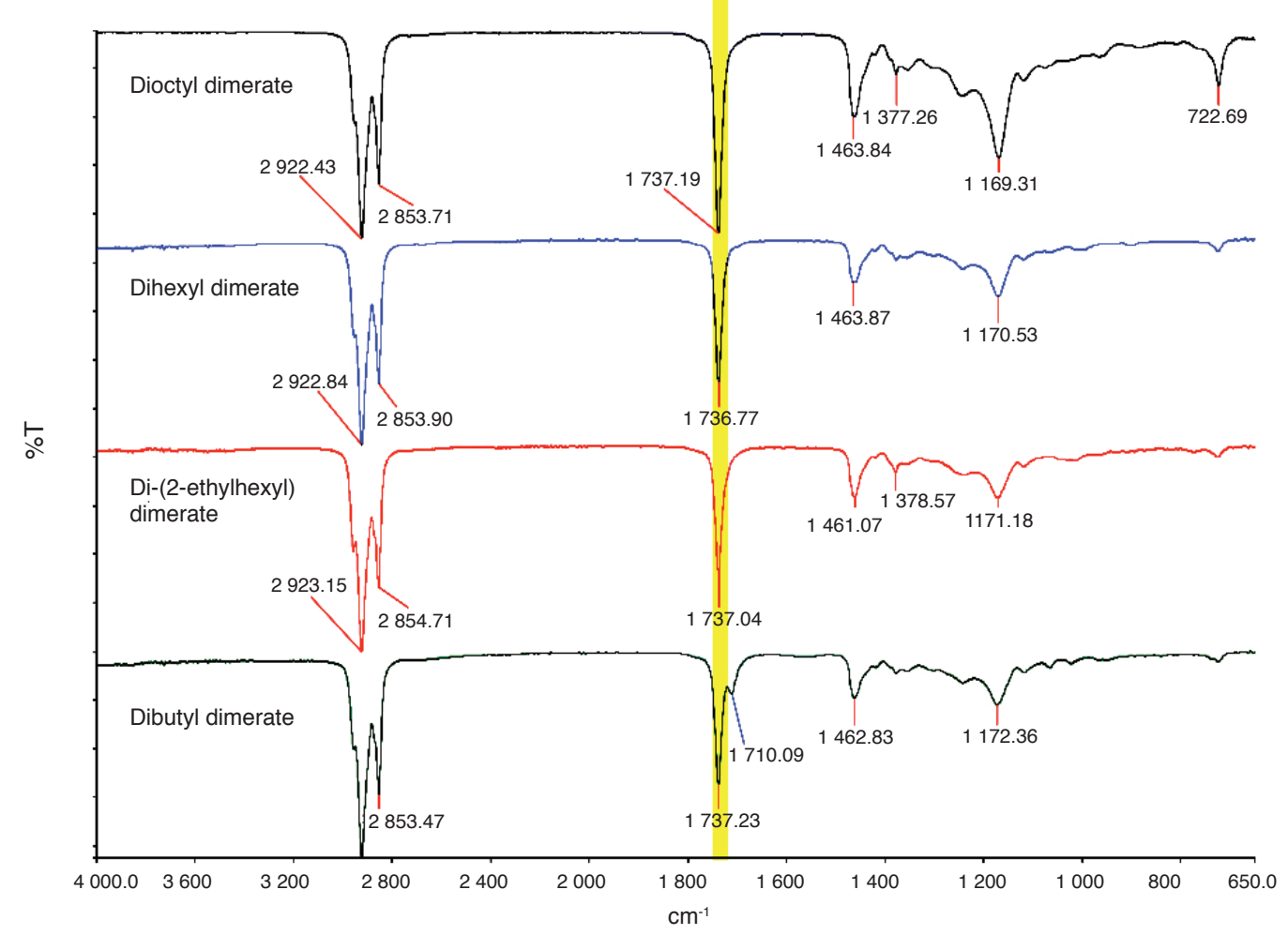

Figure 10. Infra-red overlay of synthesised $C_{36}$ dimerate esters.

alcohol. The synthesis was achieved without using any solvent or catalyst but drying agent, $3 \AA$ MS $(15 \% \mathrm{w} / \mathrm{w})$. Furthermore, the feedstock is from renewable resource. Hence, green chemistry has been applied successfully as the synthesis process including purification eliminated the release of any chemical waste to air, water and land.

\section{ACKNOWLEDGMENT}

The authors would like to thank MPOB for the financial support provided throughout the research. The technical assistance provided by Zuraidah Kamarudin and Selasiah Abdullah for the synthesis of $\mathrm{C}_{36}$ dimerate ester and analysis works is greatly 
appreciated. We would also like to thank Rosnah Ismail, Senior Research Fellow for her guidance and advice in writing the article.

\section{REFERENCES}

ALDRICH, S (2015). Molecular sieves [WWW Document]. Sigma Aldrich Co. URL http://www. sigmaaldrich.com/chemistry / chemical-synthesis / learning-center / technical-bulletins / al-1430 / molecular-sieves.html, accessed on 18 August 2016.

ANASTAS, P T and WARNER, J C (1998). Green Chemistry: Theory and Practice. Oxford University Press, New York.

ASHWORTH, I W; BUSH, E; CHAN, L C; CHERRYMAN, J; COX, B G; MUIR, J; KORUPOJU, S R and KESHWAN, J (2012). Where has my acid gone? Understanding the self-catalyzed esterification of maleic acid in methanol during salt formation. Org. Process Res. Dev., 16: 1646-1651. DOI: 10.1021 / op3001959.

BUENEMANN, T F; BOYDE, S; RANDLES, S and THOMPSON, I (2003). Synthetic lubricants - nonaqueous. Fuels and Lubricant Handbook: Technology, Properties, Performance and Testing (Totten, G E; Westbrook, S R and Shah, R J eds.). ASTM International.

BURG, D A and KLEIMAN, R (1991). Preparation of meadowfoam dimer acids and dimer esters, and their use as lubricants. J. Amer. Oil Chem. Soc., 68: 600-603. DOI: 10.1007/BF02660161.

CHANDA, M (2006). Condensation (step-growth) polymerization. Introduction to Polymer Science and Chemistry: A Problem Solving Approach. CRC Press. p. 236-245.

DUDA, A and PENCZEK, S (2005). Mechanisms of aliphatic polyester formation. Biopolymer Online. Wiley-VCH Verlag GmbH \& Co. KGaA. p. 381.

ELSASSER, A F and MCCARGAR, L A (2001). Method of preparing dimeric fatty acids and/or esters thereof containing low residual interesters and the resulting dimeric fatty acids and/or dimeric fatty esters. US 6187903.

GHASEM, N (2014). Polymerization of hot melt adhesives from dicarboxylic fatty acid for introductory organic chemistry laboratories. J. Laboratory Chem. Educ., 2: 85 - 89. DOI:10.5923/j. jlce.20140205.02.
HENRY, C J and TIERNEY, R B (1962). Nonsquawking automatic transmission fluid. US patent $3,039,967$.

KALE, V; SUBBARAO, R; LAKSHMINARAYANA, G and RAO, M B (1991). Studies on kinetics and preparation of $\mathrm{C}_{36}$ dimer acid esters. J. Amer. Oil Chem. Soc., 68: 583-584.

KIRBASLAR, I; BYAKAL, B and DRAMUR, U (2001). Esterification of acetic acid with ethanol catalysed by an acidic ion-exchange resin. Turk. J. Engin. Environ. Sci., 25: 569-577.

MPOB (2005a). Method of test for palm and palm oil products: fatty acids determination of acid value. MPOB Test Methods. MPOB, Bangi. p. 33-36.

MPOB (2005b). Methods of test for palm oil and palm oil products: determination of acidity. $M P O B$ Test Methods. MPOB, Bangi. p. 188-193.

MA, F; CLEMENTS, L and HANNA, M (1998). The effects of catalyst, free fatty acids, and water on transesterification of beef tallow. Trans. Asae, 41: 1261-1264.

MANDAKE, M B; ANEKAR, S V and MUMBAI, N (2013). Kinetic study of catalyzed and uncatalyzed esterification reaction of acetic acid with methanol. Amer. Int. J. Res. Sci. Technol. Eng. Math., 3: 114-121.

MANDAL, B M (2013). Step polymerization. Fundamentals of Polymerization. World Scientific Publishing Co. Pte Ltd, Singapore. p. 37-41.

MASKILL, H (1990). The Physical Basis of Organic Chemistry. Oxford, New York.

MATUSZAK, A H and CRAVEN, W J (1958). Improved lubricating composition. US patent $2,849,399$.

MOHAMMAD, $\mathrm{H}$; ALMAHNA, $\mathrm{N}$ and FALAH, A (2013). Kinetics of reaction of hydrogenated dimer fatty acid $C_{36}$ with 2,7 diamino fluorene and determination of thermodynamic constants. Phys. Sci. Res. Int., 1: 76-88.

MORWAY, A J; RAHWAY, C; YOUNG, D W and COTTLE, D L (1954). Lubricating grease prepared from the esters of the dimer of linoleic acid. US $2,673,184$.

PARK, J Y; WANG, Z M; KIM, D K and LEE, J S (2010). Effects of water on the esterification of free fatty acids by acid catalysts. Renew. Energy, 35: 614618. DOI:10.1016/j.renene.2009.08.007. 
PATIL, K D and KULKARNI, B D (2014). Kinetics studies on esterification reaction of acetic acid with iso-amyl alcohol over ion exchange resin as catalysts. Int. J. Eng. Res., 3: 488-493.

PÖPKEN, T; GÖTZE, L and GMEHLING, J (2000). Reaction kinetics and chemical equilibrium of homogeneously and heterogeneously catalyzed acetic acid esterification with methanol and methyl acetate hydrolysis. Ind. Eng. Chem. Res., 39: 26012611. DOI:10.1021/ie000063q.

RANDLES, S J (2006). Esters. Synthetics, Mineral Oils, and Bio-based Lubricants Chemistry and Technology (Rudnick, L R ed.). Taylor \& Francis Group, Boca Raton. p. 49.

RUTKOWSKI, A J and SZYKOWSKI, J P (1976). Biodegradable seal swell additive with low toxicity properties for automatic transmission fluids, power transmission fluids and rotary engine oil applications. US 3,974,081.

SANZ, M T; MURGA, R; BELTRÁN, S; CABEZAS, $\mathrm{J}$ L and COCA, J (2002). Autocatalyzed and ionexchange-resin-catalyzed esterification kinetics of lactic acid with methanol. Ind. Eng. Chem. Res., 41: 512-517. DOI:10.1021/ie010454k.
SYED AB RAHMAN, S A; ABU BAKAR, M Z and AHMAD, $Z$ (2010). Preliminary study of the heat release from esterification process. Int. J. Eng. Technol., 10: 1-4.

TAN, CP and NEHDI, IA(2012). The physicochemical properties of palm oil and its components. Palm Oil Production, Processing, Characterization and Uses (Lai, O M; Tan, C P; and Akoh, C C ed.). AOCS Press. p. 377-391.

TIERNEY, R B (1960). High temperature lubricant composition. US patent 2,922,763.

TOOR, A P; SHARMA, M; KUMAR, G and WANCHOO, R K (2011). Kinetic study of esterification of acetic acid with n-butanol and isobutanol catalyzed by ion exchange resin. Bull. Chem. React. Eng. Catal., 6: 23 -30.

TRAN, H L; RYU, Y J; SEONG, D H; LIM, S M and LEE, C G (2013). An effective acid catalyst for biodiesel production from impure raw feedstocks. Biotechnol. Bioprocess Eng., 18: 242-247. DOI:10.1007/ s12257-012-0674-1.

ZEKI, N S A; AL-HASSANI, M H and AL-JENDEEL, H A (2010). Kinetic study of esterification reaction. Al-Khwarizmi Eng. J., 6: 33-42. 